SEES Research Series

Research Article I

\title{
An Analysis of Trends in Road Transport and Policy Directives to Address Emissions
}

\author{
Kerry Anne Cort, Denise Simmons \& Navin Chandarpal
}

\begin{abstract}
Increase in vehicle usage in a developing nation like Guyana contributes to projected global greenhouse gas emissions. Although a net emitter, Guyana still shares the global responsibility to mitigate against climate change. This preliminary study examined the current state of vehicle trends and its effect on creating an efficient road transport sector. The study used a mixed method. Both quantitative and qualitative data were used to converge broad numeric trends in the vehicles registered and the issues related to policy implementation as described by key transportation and environmental agencies. The annual rate of increase for road vehicles was found to be $15 \%$ with an increase in passenger cars and light-duty vehicles. The trends also reveal that these vehicles are mostly used and reconditioned. The policy measures recommended by this study included changing the current taxing system and improving efficiency in passenger travel. In this regard, the value of environmental consideration in the transport sector of the country needs to be strengthened and greater efforts are needed to investigate and monitor our vehicle fleet.
\end{abstract}

Keywords: emissions, vehicles, climate change, passenger cars, estimations, trends

\section{Introduction}

\section{Background}

The environmental agenda of Guyana became ever more important for its development priorities after the Rio Summit held in 1992. As a requirement of the United Nations Framework Convention on Climate Change (UNFCCC), Guyana prepared and submitted its Initial National Communication (INC) in 2002 to the Conference of Parties of the Convention (COP). As part of the project, a greenhouse gas inventory was completed. The inventory for energy usage is currently estimated based on total fuel used within the country and this is considered a "top down" approach. In a narrow sense, there has not been any national scientific study or data collection for the evaluation of emissions from road transport directly based on vehicle activities. To broaden the perspective, global trends in vehicle ownership, usage, and related carbon emissions have been widely studied. The literature covers a broad spectrum from economic 
methods (Davis \& Khan, 2009; Pongthanaisawan et al., 2010) to analytical techniques (OECD, 2002; Liaquat, 2010).

In recent years, the overwhelming concentration of motor vehicles in developing countries contributed significantly to increased carbon emissions (Onursal et al., 1997), especially carbon dioxide and other pollutants responsible for climate change. Estimates from the Guyana Revenue Authority (GRA) in 2010, show that there are 128,000 vehicles on the roadways of Guyana. While the number of new vehicles (with lower emissions) is increasing, old and poorly maintained vehicles (with high emissions) are still being imported and operated. There is a significant demand and incentive to purchase these used vehicles. The Government of Guyana pursued a policy for permitting the importation of reconditioned vehicles for many general reasons: namely to assist with agricultural development, to make vehicles more affordable, and to ensure public and private transportation is readily and reasonably available to the Guyanese populace. The condition of these vehicles may be an increasing factor for deteriorating air quality and congestion, especially with the concentration of wealth around cities like Georgetown.

Although Guyana is considered a net emitter (LCDS, 2010), the country embarked on the path to a low carbon economy by maintaining its standing forests, among other initiatives. However, in moving towards a low carbon pathway, the country needs to define the carbon intensity of the road transport sector. The unresolved contributions of carbon dioxide to this sector may have economic implication to the commitments provided through our Low Carbon Development Strategy (LCDS). A national multi-faceted bottom-up approach is required to identify better procedures and more efficient methods within this sector. In this way, it is easier to identify areas and gaps needed for efficient passenger travel. Nevertheless, for low income countries like Guyana, the challenge is how to address economic development and poverty alleviation while engaging in climate change adaptation and low carbon development efforts.

This research incorporates vehicle activity and condition into the greenhouse gas inventory analysis within Guyana. The intent of the concurrent design was to embed one smaller form of data within the context of another larger data collection in order to analyse different types of questions. The study utilised the bottom-up approach, which examines the effect of emissions based on vehicle miles travelled and fuel efficiency, rather than the standard inventory of the country's overall fuel consumption examined in the top down approach (Davies, n.d.). The objectives of the research are: to examine the trends associated with types of vehicles registered in Guyana for the period 200I to 2010; and to recommend possible policy measures aimed at reducing emissions from road transport in Guyana.

\section{Literature Review}

Literature on climate change and transport is extensive since the awareness of the global scale of emissions of greenhouse gases (GHGs) has increased over recent years. In this section, we summarise and analyse the arguments posited by various authors, on addressing underlying factors and theories for vehicular emission and its influence on climate change and policy in the wider world. Research done in Guyana is also captured in this review. 


\section{How Vehicles Affect Carbon Dioxide Emissions}

Generally, it is assumed that once a motor vehicle is driven, it is considered used; the more it is driven increases the possibility of mechanical issues developing, thus the less efficient it becomes. As a vehicle becomes outdated and less efficient to newer models and technologies, more fuel is required to drive a shorter distance and in that case, the car emits more greenhouse gases. Common issues that affect motor vehicle emission rates are seen in Table I.

Table I: Typical Factors Affecting Motor Vehicle Emissions

\begin{tabular}{|llll|}
\hline $\begin{array}{l}\text { Vehicle } \\
\text { Parameters }\end{array}$ & Fuel Parameters & $\begin{array}{l}\text { Vehicle Operating } \\
\text { Conditions }\end{array}$ & $\begin{array}{l}\text { Environmental } \\
\text { Parameters }\end{array}$ \\
\hline Vehicle class & Fuel type & Average vehicle speed & Altitude \\
\hline Model-year & Oxygen content & $\begin{array}{l}\text { Load (air conditioner, } \\
\text { heavy load) }\end{array}$ & Humidity \\
\hline Fuel delivery system & Fuel volatility & Cold or hot start & Ambient temperature \\
\hline $\begin{array}{l}\text { Emissions control } \\
\text { system }\end{array}$ & Sulphur content & $\begin{array}{l}\text { Diurnal temperature } \\
\text { changes }\end{array}$ \\
\hline $\begin{array}{l}\text { On-board computer } \\
\text { system }\end{array}$ & Benzene content & \\
\hline $\begin{array}{l}\text { Inspection and } \\
\text { maintenance }\end{array}$ & $\begin{array}{l}\text { Olefin and aromatic } \\
\text { hydrocarbons }\end{array}$ & \\
\hline & Lead and metals content & \\
\hline
\end{tabular}

Source: Guensler, 1994 (cited in Onursal, 1997)

Kahn (1996) conducted empirical studies to show how vehicle emissions vary by model and how such estimates provide information about the benefits of past regulatory regime shifts. Using cross-sectional data, Kahn found that a 1975 model car pollutes significantly less than car models of 1974. The overall findings showed that aggregate vehicle emissions were falling and gave evidence that emissions fall when new-car emissions regulations become more stringent. It explained that microdata created by vehicle emissions testing programs, such as those in Table I, offer the opportunity to disaggregate emissions trends and to quantify how vehicle emissions vary by model, year, make, size, and used-car status.

Although the research does not focus on the economics of vehicle importation and emissions, the issue of trade of used vehicles and consumption-based pollution still presents an important debate. Davis et al. (2009) examined the environmental consequences of international trade in used vehicles. The study emphasised that trade in used vehicles raises policy issues when it comes to international free trade and global efforts to mitigate greenhouse gas emissions. The study also found that differences in operating costs and willingness-to-pay for quality, imply that used vehicles will tend to be traded from high-income countries to low-income countries. In addition to this scale effect, trade affects the composition of vehicles in all countries. Therefore, since older vehicles tend to emit substantially higher levels of pollutants, trade may have a large impact on environmental quality in both importing and exporting countries. According to United Nations Environmental Programme (UNEP) Passenger Vehicle Standards \& Fleets (2010), Guyana has no import restrictions for used vehicles, indirectly affecting the state of our emissions. Most vehicles imported into Guyana are made in Japan. By incorporating lessons learned from studies such as 
those by Khan and Davis, the Licence and Revenue Office and Transport Planning Unit may have a better understanding of the effects of the country's vehicle fleet.

\section{Motor Vehicle Increase and Climate Change}

There is an expected future growth in per capita vehicle ownership rates in regions such as Latin America and Asia (Eggleston \& Walsh, 1993). The IEA/SMP (2004) transport model examined trends of vehicle ownership and usage. The model showed that in the developing world, vehicle ownership has consisted of highly polluting, used vehicles. The study explained that vehicle ownership may not be considered as an emissions issue, where some countries focus emission reduction strategies on vehicle usage and not ownership. The IEA explained that an older vehicle fleet in conjunction with poor maintenance practices and limited vehicle testing can mean that the impacts of motorisation on developing nations are many times worse than an equal level of motorisation in developed nations. Such trends have not been widely studied in Guyana but provide useful feasibility analogies for the transport sector. The changes in Guyana's vehicle ownership have only become considerable in recent years.

Schipper, Peake and Marie (1997) suggested that the values attached to the externality of carbon emissions tend to be low compared to those associated with other problems. What their study explained was that $\mathrm{CO}_{2}$ by itself may not be "felt" as a strong stimulus for change, but by making changes to deal with other problems related to transport, this may affect areas such as traffic and ultimately emissions. Other externalities in transport may be more serious as they threaten Guyana today (such as congestion, deteriorating air quality and inefficient public transport) and thus, provide a feedback into the technologies and policies needed to reduce the problems. "Were $\mathrm{CO}_{2}$ emissions not increasing, authorities could wait for more information on possible damages before taking action..." (Schipper, Peake \& Marie, 1997). However, as policy makers are "under pressure" from environmental authorities, it is becoming ever more important to understand the underlying factors for rising emissions.

\section{Measures for Emission Reduction}

Various countries have begun to evaluate the role of transport in fuel demand and emissions. Fabian's study (2009) in the Philippines was an initial attempt to analyse the current and future emissions of $\mathrm{CO}_{2}$ and particulate matter from land transport as well as estimate the impacts of selected sustainable and low-carbon transport policies. His study had similar objectives to the present research. By formulating policy scenarios, it found that demand management measures had relatively substantial reductions compared to fuel efficiency and technological measures. Demand management refers to measures including road pricing or congestion pricing, higher parking fees or restricted parking in central business districts, or even the overall reduction of trips due to better urban planning. The potential of such policies in Georgetown was inquired upon within the current research.

As pointed out by King (2007) and reiterated by Michaelis (1996), socio-economic and cultural policy initiatives stand out as the most effective focus for reducing $\mathrm{CO}_{2}$ emissions. The study also found that governments pay much attention to developing new technologies. Guyana is exploring the use of alternative fuels (LCDS, 2010). This is found to be one way of reducing GHG emissions; 
however, technology might not provide the whole answer, and more research is needed into the possible role of developments in preference and lifestyle.

In summary, most studies that were reviewed examined transport emissions based on GHG increase along with emissions in the context of climate change and policy measures needed to curb the increase. These studies highlighted to the lack of investigation and fusion of vehicle fleet and the environmental issues within the transport sector in Guyana. Before policy and decisionmakers develop strategies to reduce transport-related emissions, they need to understand how and why people make transport choices and what influences the nature of the transport system.

\section{Methodology}

\section{Research Design}

This study used a concurrent embedded strategy of mixed methods. It was important to use this strategy to gain a broader perspective as a result of examining data from the two methods. This helped to integrate the quantitative information gained through trend analysis with qualitative interview responses. The data could not be necessarily compared, but resided side by side as different representations that provide an overall composite assessment of the problem.

To easily manage and represent the data, the researcher used the standardised vehicle categories set by the Intergovernmental Panel on Climate Change (IPCC) to group the vehicle types present in Guyana described by the Licence and Registration Office (LRO). Due to the scope of this research, we excluded all heavy-duty agricultural vehicles; namely, excavators, bulldozers, cranes, all-terrain vehicles, tractor/trailers, articulated vehicles, lorries, and draglines. The standard vehicle categories formulated for the study are summarised in Table 2.

Table 2: Standard Vehicle Categories Used in Study

\begin{tabular}{|ll|}
\hline Vehicle Category & LRO Vehicle Types \\
\hline Passenger cars (PC) & Car, hearse, jeep, wagon \\
\hline Light Duty Vehicles (LDV) & Land rover, lorry, pick-up, van \\
\hline Urban buses and coaches (UB) & Motor bus, mini bus \\
\hline Motorcycles (MC) & Cycle \\
\hline
\end{tabular}

\section{Methodology for Objective I: Trends of Registered Vehicles from 200 I-20 I0}

Data Collection

The main form of data collected was primary data taken from the LRO's electronic database and the Guyana Energy Agency (GEA), while other inferences were made from secondary data sources. Accurate data for the ten year period under consideration was not available. As such, some variables that would be useful to the study were not included in trend analyses, such as the age of manufacture of the fleet, the source of vehicles, odometer readings or engine capacities. Further, correlation analysis was thus reduced. 


\section{Variables}

In observing the trends of registered vehicles within the set time period, the following key variables were considered:

- Total Number of Registrations

- Categorisation of vehicles

$\circ$ Weight characteristics

- Type of vehicle

- Condition of Vehicle: new $(\mathrm{N})$, used $(\mathrm{U})$ and reconditioned $(\mathrm{R})$

\section{Methodology for Objective 2: Policy measures for reduction possibilities in road emissions}

Interviews were conducted to obtain the views of key informants. Fourteen agencies were selected that were either directly or indirectly related to the transport sector and environment. Data were collected by means of an interview schedule containing thirteen items. The questions inquired about measures required for emission reductions and the state of emissions data and collaboration. The views of the respondents were summarised and analysed based on recurring themes.

\section{Ethical Issues}

The researcher had an ethical obligation to the research community in respecting the data that was supplied by various agencies and organisations. The confidentiality of the views of interviewees was upheld and no names were published in the official document. All principles and codes of conduct were adhered to for liberal information sharing and good relations with personnel.

\section{Results}

Figure I represents the total number of vehicles, of all types (excluding agricultural) that have been registered by the LRO for the period 1993 to 2010 . Since the sample follows a normal population distribution, the Regression Line was plotted. Overall, the exponential trend reveals a positively increasing slope. The $\mathrm{R}^{2}$ value indicates that along the variable of time, only $51 \%$ of the data is explained by the increasing trend and other factors may contribute to the rise in registrations.

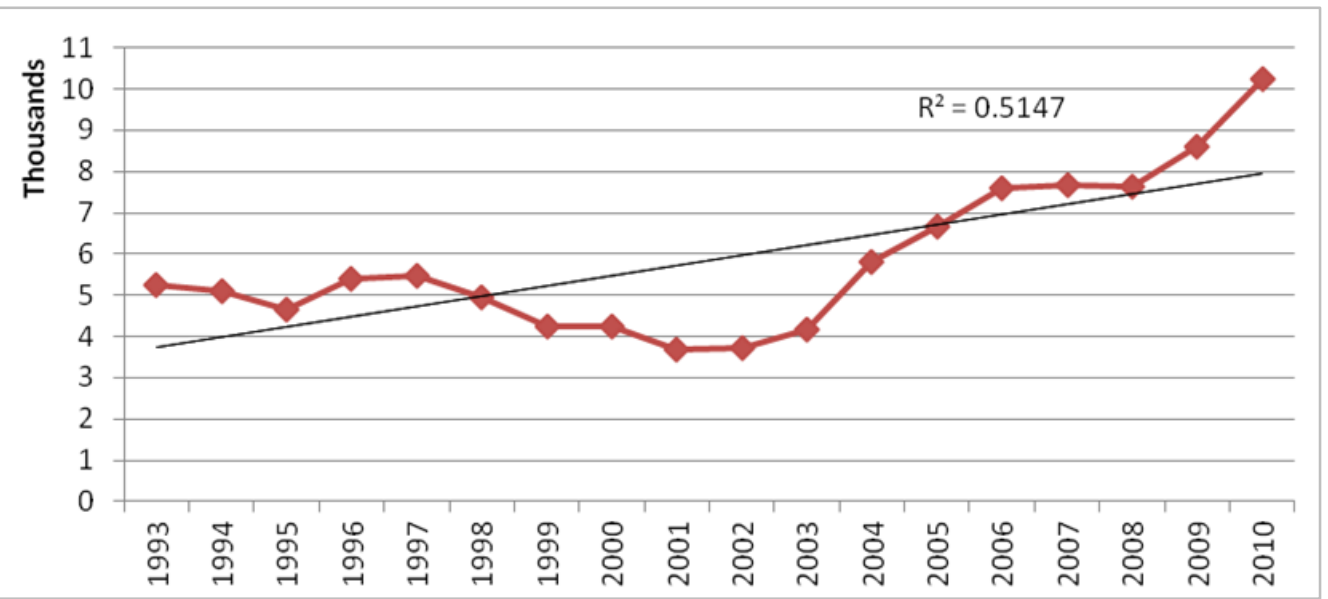

Figure I: Total Vehicles Registered, 1993-2010 
Figure 2 illustrates a comparison of the trends shown by vehicles of different categories. The trends show that more passenger cars are registered per year than any other vehicle category. The one-way ANOVA was used to test the variance between sample means. The null hypothesis is that there is no difference between the mean rate of change of the independent categories of vehicles $\left(\mathrm{H}_{0}: \mu_{1}=\mu_{2}=\mu_{3}\right.$ etc). In essence, all vehicles change at the same rate each year. The alternative is there is a difference between means $\left(\mathrm{H}_{\mathrm{a}}: \mu_{1} \neq \mu_{2}\right)$. The test revealed a $P$ value of $0.382 \mathrm{I}$. Since this value is greater than 0.05 at the 95 percent Confidence Interval $(\mathrm{Cl})$, there is no significant difference between mean rates of change over the ten years. This means that all vehicle categories were changing at a fairly comparable rate of registration over the ten year period. The rate of change may not be statistically significant, but as indicated in Figure 2, the average annual change for passengers cars are greater than other categories.

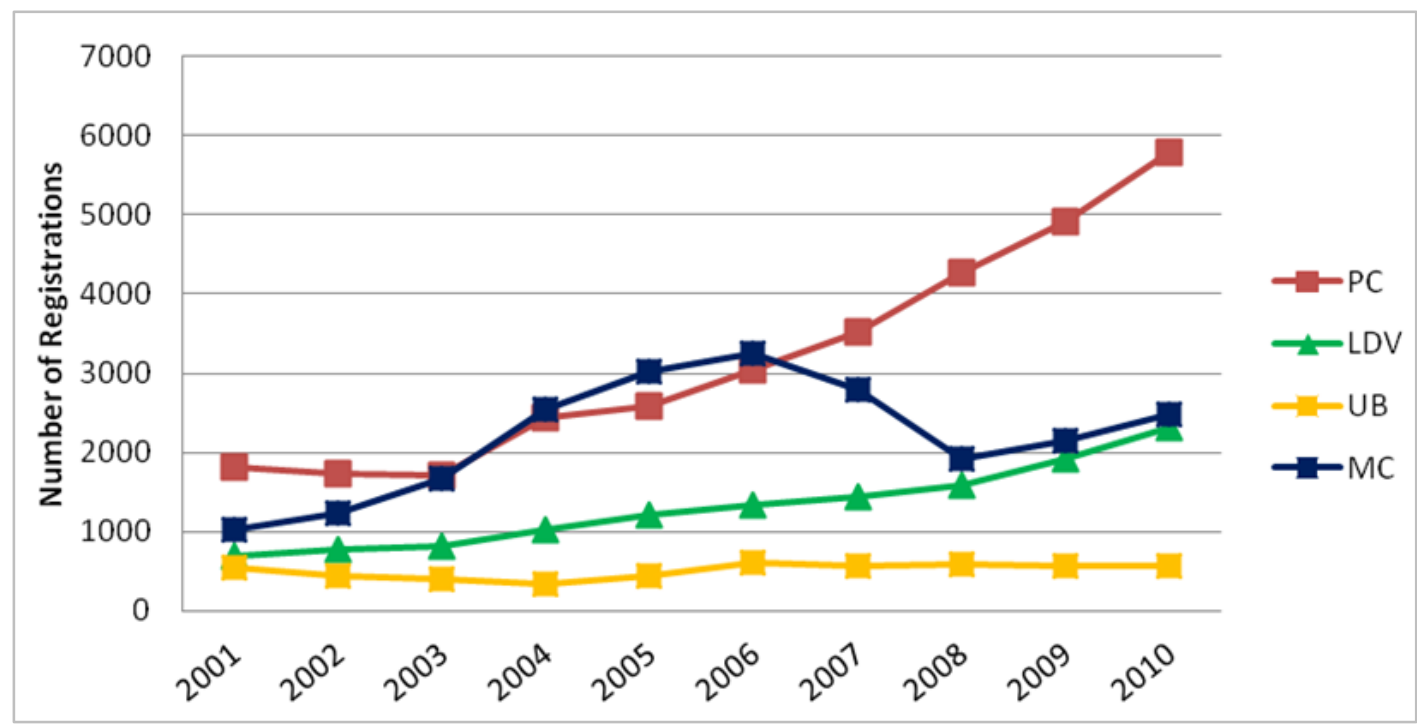

Figure 2: Total Vehicles by Category

The comparison of rates from the base year $200 \mathrm{I}$ gives a clearer representation of changes within categories as represented in the table below. From 2004 there was a fairly sharp rate of increase of $42 \%$ in passenger cars and $52 \%$ of motorcycles compared to other categories. From 20032006 the number of MC increased at a greater rate than PC, after which the rate of MC declined sharply while PC rose. Table 3 indicates that by the year 2009, rate of increase of LD surpassed that of PC and MC. Other variables (such as increased incomes and horizontal growth of urban areas) may have an influence on this observed trend. 
Table 3: Percent rate of change for each vehicle category

\begin{tabular}{|l|r|r|r|r|}
\hline Year & $\begin{array}{r}\text { PC } \\
\text { Rate }\end{array}$ & $\begin{array}{r}\text { LDV } \\
\text { Rate }\end{array}$ & $\begin{array}{r}\text { UB } \\
\text { Rate }\end{array}$ & $\begin{array}{r}\text { MC } \\
\text { Rate }\end{array}$ \\
\hline 2002 & $-4 \%$ & $12 \%$ & $0.15 \%$ & $21 \%$ \\
\hline 2003 & $-1 \%$ & $6 \%$ & $0.20 \%$ & $36 \%$ \\
\hline 2004 & $42 \%$ & $24 \%$ & $0.21 \%$ & $52 \%$ \\
\hline 2005 & $6 \%$ & $19 \%$ & $0.39 \%$ & $19 \%$ \\
\hline 2006 & $18 \%$ & $10 \%$ & $0.31 \%$ & $7 \%$ \\
\hline 2007 & $16 \%$ & $7 \%$ & $0.16 \%$ & $-14 \%$ \\
\hline 2008 & $21 \%$ & $10 \%$ & $0.18 \%$ & $-32 \%$ \\
\hline 2009 & $15 \%$ & $21 \%$ & $0.16 \%$ & $12 \%$ \\
\hline 2010 & $18 \%$ & $21 \%$ & $0.18 \%$ & $16 \%$ \\
\hline Mean & $17.6 \%$ & $13.8 \%$ & $0.19 \%$ & $-2.2 \%$ \\
\hline
\end{tabular}

Vehicles may be categorised as new, used, or reconditioned, according to LRO types. In essence, a new vehicle is one that has not been driven, a used vehicle is one that has been driven extensively. and a reconditioned vehicle is one that has mechanical changes to the used vehicle to improve its condition. Figure 3 illustrates that comparatively the registrations of new, used and reconditioned vehicles over the ten year period.

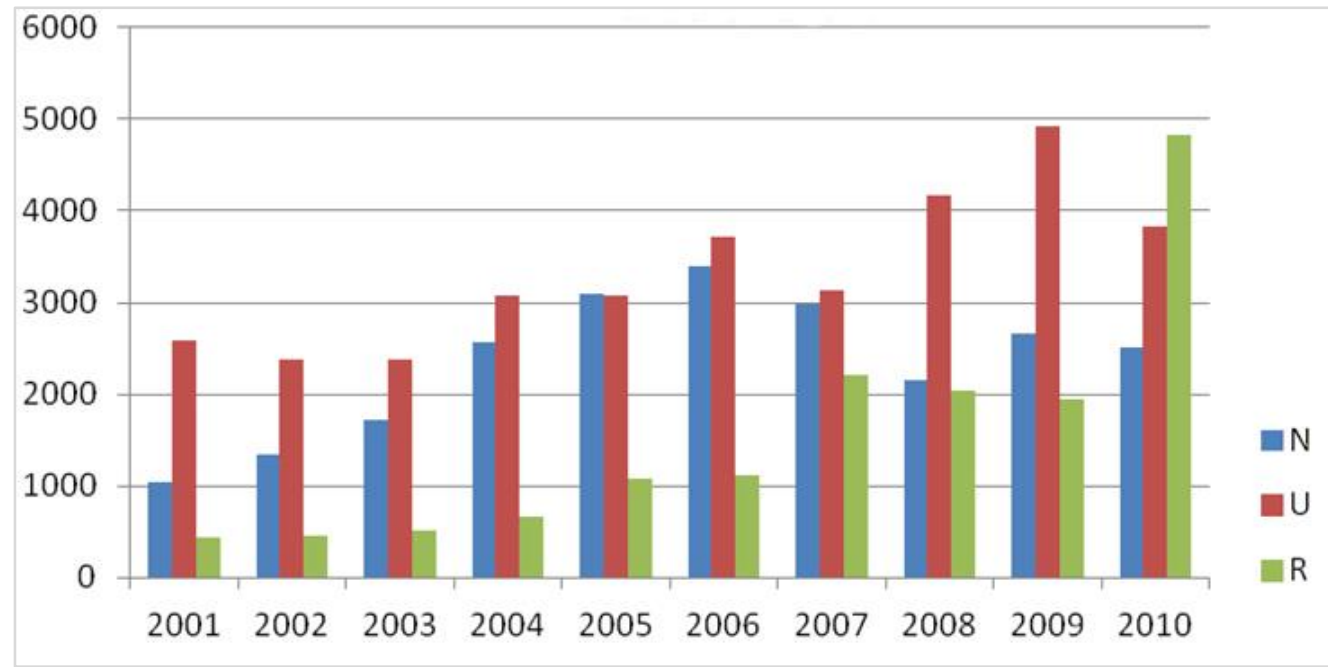

Figure 3: Total registrations based on vehicle condition

Table 4 illustrates the percentage rate of change based on the vehicle condition (new, used or reconditioned) over the ten-year time period. It shows that reconditioned vehicles increased significantly in 2010 with a rate of change of $149 \%$ while the use of new vehicles declined by $6.1 \%$ and by $22.3 \%$ for used vehicles. This showed an improved conversion from solely used to reconditioned vehicles. 
Table 4: Percent rate of change for different vehicle conditions

\begin{tabular}{|r|r|r|r|}
\hline Year & N-Rate & U-Rate & R-Rate \\
\hline 2002 & $30.1 \%$ & $-8.1 \%$ & $5.4 \%$ \\
\hline 2003 & $28.2 \%$ & $-0.25 \%$ & $10.2 \%$ \\
\hline 2004 & $49.2 \%$ & $30 \%$ & $32.5 \%$ \\
\hline 2005 & $20.6 \%$ & $-0.2 \%$ & $60.9 \%$ \\
\hline 2006 & $9.6 \%$ & $20.8 \%$ & $2.7 \%$ \\
\hline 2007 & $-12.3 \%$ & $-15.7 \%$ & $99.8 \%$ \\
\hline 2008 & $-27.6 \%$ & $32.8 \%$ & $7.8 \%$ \\
\hline 2009 & $23.8 \%$ & $18.4 \%$ & $-5.2 \%$ \\
\hline 2010 & $-6.1 \%$ & $-22.3 \%$ & $148.7 \%$ \\
\hline
\end{tabular}

The null hypothesis is that there is no difference between mean rate of change of the independent conditions of vehicles $\left(\mathrm{H}_{0}: \mu_{1}=\mu_{2}=\mu_{3}\right.$ etc). The alternative is there is a difference between means $\left(H_{a}: \mu_{1} \neq \mu_{2}\right)$. The results of the one way ANOVA show a P-value of 0.0176 . Since it is less than 0.05 it is considered statistically significant and there is a statistically significant difference between the mean rate of change of new, used, and reconditioned vehicles over the ten year period. The LSD pairwise comparative test shows the distinction between groups. The means for each condition were $\mathrm{N}$ : 2348.I, R: 1880.4 and $\mathrm{U}: 3326.9$. The test revealed that used and reconditioned vehicles fall into different groups and their means are significantly different from each other over the ten years. Therefore the LSD shows significantly more used vehicles have been registered in Guyana than reconditioned but no significant difference between new vehicles.

\section{Discussion}

All vehicles have shown to increase at a fairly comparable rate with an observed peak beginning in 2008. There has been an increase in the number of passenger cars compared to other categories, although this was not statistically significant. Pongthanaisawan (2010) provided a study which illustrated that at the early stage of economic development of developing countries such as Thailand, the number of motorcycles predominates over private cars. He further demonstrated that economic development strongly affects the ownership of private vehicles in two ways: (I) overall private vehicle ownerships increase as the income levels grow; and (2) after personal income rises to a certain level, people will shift from motorcycle to car ownerships for their prestige, convenience, comfort, and safety. The data acquired from the LRO presented similar characteristics in the observed trends.

The percentage rate of change of new vehicles showed an overall decline from 2006 onwards while registration of used vehicles was more significant. The researcher uses the term "used" to mean more than 4 years old (Excise Division Figure pers. comm.). Age and mileage are not correlated at the LRO and as such were not evaluated. Essentially, vehicle emission testing creates a virtual census of a country's vehicle fleet. Data correlations beginning at the collection stage would enhance such estimations. Also, policies - particularly car restriction policies - are quite important as complementary measures in supporting public transport and non-motorised options as highlighted in the study by Wright and Fulton (2005). Notably, it was stated that a feasible policy directive applicable to the transportation sector of Guyana in the short term would be the 
restriction of the importation of foreign used vehicles to cars that are a maximum of five (5) years old (GINC, 2002). Based on the responses of the key informants, there were several recurring themes that will be discussed to aid in answering the second objective.

\section{Vehicles and Importation}

For the most part, the majority of interview respondents agreed that vehicle importation has been increasing, but whether this was of concern and emission control is needed, was differential. In Guyana's context, it was described as critical because of the policy encouraging importation of used vehicles and higher duties for newer vehicles compared to reconditioned vehicles.

Some other perspectives were that from the viewpoint of national development, the average household simply has more disposable income to buy these vehicles. It was also described as a reflection of quite significant economic development. However, this analysis was scrutinised by others who said that an increase in personal vehicles is not necessarily needed for development in urban areas. Georgetown is reaching a point of heavy reliance on cars and more personal vehicles which may not breed efficiency in an urban centre. Wright (2004) states that if nations follow the same path of automobile dependence as developed nations, there is little that technological advances can offer to offset such a monumental increase in motorisation and its subsequent emissions.

\section{Fiscal Measures}

Many respondents shared the view that changes in the tax system could help to improve the overall quality in the vehicle fleet of Guyana. One view was that we cannot eradicate reconditioned vehicles immediately but we can certainly reduce the duty on new vehicles. Several reasons were put forth on why importing new vehicles is advantageous to Guyana; for instance:

- "Guyana is not a producer of spare parts. All the spear parts for reconditioned vehicles have to be imported and these are the vehicles that require more parts. This means there's foreign exchange leakage from our economy from our already limited foreign exchange."

- Used and reconditioned vehicles tend to consume more fuel. Since Guyana does not produce fuel, this means some additional importation of fuel needs to be imported to supply an older fleet. Again this is some leakage for the country.

Other than taxes, certain incentives and measures present in other countries were thought to be useful in our case. For instance, it was suggested that a cost should be attached to parking in Georgetown and that there is no benefit of allowing free parking in such a city centre. It was highlighted that in the UK there is parking outside the city areas and free transportation available to the inner parts. Also, the insurance premium on reconditioned vehicles could be made higher than newer vehicles to discourage consumers from the latter option.

\section{Alternative Fuels}

There were contrasting views on Guyana's readiness to pursue ethanol as an alternative fuel source. It was stated that Guyana is actively pursuing an Agro-Energy policy with specific focus on biofuels. The production of ethanol as a blend in gasoline and biodiesel are being reviewed for possible implementation. The Ministry of Agriculture and Institute of Applied Science and Technology (IAST) have begun conducting lab studies in this area by testing the yield of feed stocks such as sorghum and sugarcane. However, this testing process has been slow. 


\section{Transport Modes and Routes}

Another factor that was considered to be necessary in improving the overall efficiency of road transport was the entire transport network, which has an influence on vehicle usage. It was conveyed to the researcher that there has been considerable work done to improve the quality of roadways, but at the same time there has not been an overall increase in the number of roads. "So within the urban setting and coastal road network, although we have improved efficiency, capacity still remains quite limited". As a result, a bottle-neck of traffic is created during rush hour periods mainly along the East Bank of Demerara. An improved system would include such a network that reduces the number of trips to move the same number of persons while transporting more people. More passenger and bicycle spaces should also be available.

"We need to start embracing passenger per miles travelled."

Noteworthy was the need to offer incentives for car-pooling, and routes that encouraged minibuses travelling at full loads. Respondents also discussed the need to improve public transport. One responder elaborated on the inefficiency of the minibus for commuter traffic in urbanised centres. He stated that the overhead cost in a fifteen (I5) seater is borne by thirteen (13) people when compared to a larger bus where a greater number of persons would bear the cost. He further stated that while a minibus may execute more trips, the greater issue is safety.

"The public transport should be subsidised more and instead of being a privatised system should fall under the Public Utilities Commission. This sector is not very respected and is considered dangerous."

Land use issues were also highlighted; the lack of adequate urban planning could lead to more vertical instead of horizontal growth which would require more transport needs. Infrastructure, like bridges, and enforcement of tolls can impact decisions on where people live and work. As one informant stated: "We can start looking at reducing the need to commute"; signalling that out-sourcing jobs and telecommuting are newer and cheaper ways that require less energy.

\section{Data Management and Emission Inventory}

Transport is a compartment of the Energy Sector and all emission estimations are done through the GEA. The greatest challenge is getting data on time, in the required format, and complete for all periods and categories. There is need for proper collection, disaggregation and storage for easy retrieval. There must be proper feasibility analysis and more centralised planning so that there is better understanding of links between energy and transport, and other sectors.

In 2008 the License and Revenue Office took steps to shift their manual system to a computerised database. This resolved data management problems and included other data areas like engine type. There still remains a gap in data for earlier years and other variables such as the age of vehicles, source, and mileage. In all, it was said that Guyana's forthcoming Third National Communication should not "reinvent the wheel". There needs to be a verification system and the development of a national database for GHG inventory that is operable in all agencies. 


\section{Conclusion}

This study found an observed increase in the number of passenger cars from 2006 compared with other categories, but the vehicle condition poses a greater problem being mostly used vehicles. Improving the population of older vehicles on the roadways of Guyana is one of the preliminary steps to reducing our carbon footprint. Monitoring transport related emission issues, vehicle usage, and data collection is sacrificed in most cases for more seemingly tangible duties. One possible impact of the lack of baseline data is the difficulty to set environmental standards. The country's national policy is commendable for examining ways to pursue development that considers the environment. Greater effort is needed through incentives that serve to change the value system of the population, and consider more environmentally friendly options within road transport use.

\section{Recommendations}

- Better collaboration is needed between the LRO, GEA, and Transport Planning Unit to monitor vehicle data provided upon registration. Good baseline data is important for planning and policies. Good understanding of the present fleet is crucial. Data such as the age range of the fleet, source of vehicles, odometer readings or engine capacities were not included in trend analyses. Further trend analyses can be done that incorporate other economic and social indicators not highlighted in this study.

- Since carbon dioxide emissions from road transport are dependent on emissions per vehicle miles travelled, greater recognition of the importance of the collection of such parameters are necessary. There is need for a broad country-wide programme to build capacity for data collection, analysis and data management. In this way better analysis can be made with respect to vehicle usage trends rather than just vehicle importation.

- Some of the recommended policies that were described by the key transport and environment stakeholders included auto-restrictions and changing the tax regime, and discouraging the use of inefficient vehicles. Such fiscal measures can improve the incentive to purchase newer models of vehicles.

- Other demand management policies were highlighted to address the issue of increasing private vehicle usage. These included more investment in public transport and nonmotorised transport infrastructure for walking and cycling. A package of complementary measures to substantially reduce vehicle emissions and congestion may include usage of an efficient public bus transit system, bicycle infrastructure, pedestrian improvements, and carfree events. 


\section{References}

Davies, J., Gallivan, F. and Grant, M. (n.d.) Improving the transportation component of state Greenhouse Gas Inventories. US EPA, Washington. Available at: http://www.epa.gov/ttnchiel/conference/eil 7/session5/davies.pdf [Accessed 3 June, $20 \mathrm{II}$.

Davis, L. and Kahn M., 2009. International trade in used vehicles. The Environmental Consequences of NAFTA, previously NBER Working Paper 14565.

Eggleston, S. and Walsh M., 1993. Emissions: Energy, road transport - good practice guidance and uncertainty management in national greenhouse gas inventories, IPCC. Available at: http://www.ipccnggip.iges.or.jp/public/gp/bgp/2_3_Road_Transport.pdf [Accessed 21 November 2010].

Environmental Protection Agency, 2005. Emission facts: Average carbon dioxide emissions resulting from gasoline and diesel fuel. US. Environmental Protection Agency - Overview of Pollutants and Programmes. Available at: http://www.epa.gov/oms/climate/420f0500I.htm [Accessed 2 April, 20I I].

Environmental Protection Agency, 2007. Second national communication to UNFCCC: Executive summary of proposal. GEF Country site, Available at: http://www.thegefguyana.org/index.php?option=com_content\&task=view\&id $=20 \&$ Itemid=3I [Accessed 20 January, 20I I]

Fabian H. and Sudhir G., 2009. $\mathrm{CO}_{2}$ estimates from the land transport sector in the Philippines: estimates and policy implications. Proceedings of the 17th Annual Conference of the Transportation Science Society of the Philippines. Available at: <http://tssp.tripod.com/documents/I 7th_tssp/fabian.pdf> [Accessed I7 January 20 I I].

Guyana Bureau of Statistics. Available at: <http://www.statisticsguyana.gov.gy/pubs.html\#statsbull> [Accessed 29 December, 20I0].

Guyana Climate Change Action Plan, 200I. Available at: <http://www.hydromet.gov.gy/documents [Accessed I 8 January, 20I I].

Guyana Environmental Protection Act, 1996. Arrangement of Regulations. Available at: <http://www.epaguyana.org/index2.php?option=com_docman\&task=doc_view\&gid=28\&l temid=29> [Accessed 6 November 2010].

Guyana's Initial National Communication: UNFCCC, 2002. Available at: $<$ http://unfccc.int/resource/docs/natc/guyncl.pdf> [Accessed 29 December 20l0].

Hong, H., Wang, M., Johnson, L. and Dongquan, H., 2006. Projection of Chinese motor vehicle growth, oil demand, and $\mathrm{CO}_{2}$ emissions through 2050. Argonne National Laboratory-Energy Systems Division, Illinois, USA. Available at: <http://www.ipd.anl.gov/anlpubs/2006/I2/58260.pdf> [Accessed 2 I November 20 I0].

IEA/SMP, 2004. The IEA/SMP transportation model. Available at: <http://www.wbcsd.org/web/publications/mobility/smp-model-document.pdf> [Accessed I5 March, 20I I]

IPCC, Third assessment report, Annex B, Glossary of Terms Available at: < http://www.ipcc.ch/pdf/glossary/tar-ipcc-terms-en.pdf> [Accessed 7 May, 20l I].

King, D.N.T., Penny, G and Fisher G., 2007. Reducing $\mathrm{CO}_{2}$ emissions from motor vehicles: Testing the impacts of different policy initiatives. Clean Air \& Environmental Quality, 4 I (I), PP. 43-49. 
Khan, M., 1996. New evidence on trends in vehicles. RAND Journal of Economics, 27 (I), Pp. I83196.

Low Carbon Development Strategy, 2010. Office of the President, Republic of Guyana. Available at: < http://www.lcds.gov.gy/> [Accessed 27 November 2010].

Michaelis, L. and Davidson O., 1996. GHG mitigation in the transport sector. Energy Policy, 24 (I0/I I), pp. 969-984.

Organisation for Economic Co-operation and Development, 2010. Reducing transport greenhouse gas emission: Trends and data. Available at: <http://www.internationaltransportforum.org/Pub/pdf/I0GHGTrends.pdf> [Accessed 4 March 20II].

Organisation for Economic Co-operation and Development, 2002. Strategies to reduce greenhouse gas emissions from transport: Analytical methods Available at: < http://www.internationaltransportforum.org/Pub/pdf/02GreenhouseE.pdf> [Accessed 6 March 20II].

Onursal B. and Gautam S., 1997. Vehicular air pollution: Experiences from seven Latin American urban centers. Washington D.C.: World Bank.

Pongthanaisawan, J. and Sorapipatana, C., 2010. Relationship between level of economic development and motorcycle and car ownerships and their impacts on fuel consumption and greenhouse gas emissions in Thailand. Renewable and Sustainable Energy Review, 14 (9), Pp. 2966-2975.

Price, L., Michaelis, L., Worrell, E., and Khrushch, M., 1998. Sectoral trends and driving forces of global energy use and greenhouse gas emissions. Mitigation and Adaptation Strategies for Global Change, 3 (2), pp. 263-3I 9.

Schipper L., Fabian, H., and Leather, J., 2009. Transport and carbon dioxide emissions: Forecasts, Options Analysis, and Evaluation. Asian Development Bank Sustainable Development Working Paper Series, No. 9. Available at: $<$ http://www.adb.org/documents/papers/adb-working-paper-series/ADB-WP09Transport-CO2-Emissions.pdf> [Accessed 29 December, 2010].

Singh, A. et al., 2008. Trends of greenhouse gas emissions from the road transport sector in India, The Science of the Total Environment, 390 (I), PP. I24-3I.

United States Environmental Protection Agency (USEPA), 20I I. Emission factors and AP 42, compilation of air pollution emission factors. Technology Transfer Network, Clearinghouse for Inventories and Emission Factors. Available at:<http://www.epa.gov/ttnchie I/ap42/ [Accessed 3 June, 20I I].

United Nations Environment Programme (UNEP), 2010. Latin America and the Caribbean passenger vehicle standards \& fleets. Available at: <http://www.unep.org/pcfv/PDF/MatrixLACVEHMarch20I0.pdf>.

United Nations Framework Convention on Climate Change (UNFCCC), 2004. Estimation of Emissions from Road transport, Issues Relating to Greenhouse Gas Inventories. Available at:< http://unfccc.int/resource/docs/2004/sbsta/inf03.pdf> [Accessed 28 May, 20II].

Wright L. and Fulton L., 2005. Climate change mitigation and transport in developing nations. United Nations Environment Programme Transport Reviews, 25 (6), pp.69l-7I7. Available at: <http://www.gobrt.org/wright-fultonClimateChange.pdf> [Accessed I7 January 20I I]. 